\title{
Análisis comparativo sobre los resultados de las pruebas EGRA aplicadas en una red de centros educativos de Fe y Alegría, Nicaragua (2016-2018)
}

\author{
Comparative analysis of the results of the EGRA tests applied in a network \\ of educational centers in Fe y Alegría, Nicaragua (2016-2018)
}

\section{Análise comparativa dos resultados dos testes EGRA aplicados em uma rede de escolas Fe y Alegría, Nicarágua (2016-2018)}

\author{
Everardo Víctor \\ Fe y Alegría Nicaragua \\ Managua, Nicaragua \\ ni.director@feyalegria.org \\ (1) ORCID: https://orcid.org/0000-0002-7115-5750 \\ Axel Urcuyo \\ Fe y Alegría Nicaragua \\ Managua, Nicaragua \\ derechos@feyalegria.org.ni \\ (D) ORCID: https://orcid.org/0000-0003-4325-5460 \\ Neyda Zamora \\ Fe y Alegría Nicaragua \\ Managua, Nicaragua \\ investigacion@feyalegria.org.ni \\ (D) ORCID: https://orcid.org/0000-0001-7016-9619
}

Recibido - Received - Recibido: 20 / 03 / 2021 Corregido - Revised - Revisado: 20 / 08 / 2021 Aceptado - Accepted - Aprobado: 25 / 10 / 2021

DOI: https://doi.org/10.22458/ie.v23i35.3476

URL: https://revistas.uned.ac.cr/index.php/innovaciones/article/view/3476

\begin{abstract}
Resumen: El presente estudio se constituyó como una reflexión pedagógica a partir de los resultados de las pruebas EGRA aplicadas a estudiantes de primero, segundo y tercer grado, en el periodo de 2016 a 2018. La población de estudio estuvo compuesta por 5.820 pruebas estandarizadas aplicadas en 18 centros educativos atendidos por Fe y Alegría Nicaragua, para fines del análisis, se obtuvo una muestra de 4.624 pruebas, con un un $99.7 \%$ de confianza y un $1 \%$ de margen de error. Se realizó un estudio mixto, con un nivel de integración inter método mínimo, por medio del Diseño Integral Complementado (DICO). El estudio permitió realizar un análisis comparativo entre los resultados obtenidos en las pruebas aplicadas a estudiantes de primer grado en los tres años del estudio (2016-2018) de igual manera, un analisis evolutivo de primero a tercer grado en el mismo periodo. Por un lado, da pautas para determinar indicadores de medición para continuar evaluando las competencias de fluidez y comprensión lectora en el estudiantado, pero también aporta insumos para ofrecer seguimiento al desempeño docente. Se constituyó como una línea de base, para la actualización de la propuesta de mejora de la fluidez y comprensión lectora en estudiantes de primero a tercer grado de los centros educativos pertenecientes a la red de Fe y Alegría.
\end{abstract}

Palabras clave: pruebas EGRA, comprensión lectora, evaluación del estudiante, competencias del docente, práctica pedagógica.

Summary: This study became a pedagogical reflection based on the results of the EGRA tests applied to first, second and third grade students, in the period from 2016 to 2018. The study population consisted of 5,820 standardized tests applied in 18 educational centers served by Fe y Alegría Nicaragua. For the purposes of the analysis, a sample of 4,624 tests was obtained, with a confident $99.7 \%$ and a $1 \%$ margin of error. A mixed study was carried out, with a minimum inter-method integration level, by means of the Complemented Integral Design (DICO-its acronym in Spanish). The study made it possible to carry out a comparative analysis between the results obtained in the tests applied to first grade students in the three years of the study (2016-2018) and, in the same 
way, an evolutionary analysis from first to third grade in the same period. On the one hand, it provides guidelines to determine measurement indicators to continue evaluating the skills of fluency and reading comprehension in the student body, but it also provides inputs to offer monitoring of teaching performance. It was established as a baseline for updating the proposal to improve reading fluency and comprehension in students from first to third grade of the educational centers belonging to the Fe y Alegría network.

Key Words: EGRA tests, reading comprehension, student evaluation, teacher competencies, pedagogical practice.

Resumo: Este estudo foi constituído como uma reflexão pedagógica baseada nos resultados dos testes EGRA aplicados aos alunos da primeira, segunda e terceira séries o ensino fundamental no período de 2016 a 2018. A população do estudo consistiu em 5.820 testes padronizados aplicados em 18 centros educacionais atendidos por Fe y Alegría Nicarágua. Para fins de análise, foi obtida uma amostra de 4.624 testes, com um nível de confiança de $99,7 \%$ e uma margem de erro de 1\%. Foi realizado um estudo misto, com um nível mínimo de integração intermédias, por meio do Projeto Integral Complementar (DICO). O estudo permitiu uma análise comparativa dos resultados obtidos nos testes aplicados aos alunos da primeira série do ensino fundamentalnos três anos do estudo(2016-2018), bem como uma análise evolutiva da primeira à terceira série no mesmo período. Por um lado, ele fornece diretrizes para determinar indicadores de medição para continuar avaliando a fluência da leitura e as habilidades de compreensão nos alunos, mas também fornece insumos para monitorar o desempenho dos professores. Isto se constituiu em uma base para atualizar a proposta para melhorar a fluência e a compreensão de leitura nos alunos da primeira à terceira série das escolas pertencentes à rede Fe y Alegría.

Palavras-chave: testes EGRA, compreensão de leitura, avaliação dos alunos, competências dos professores, prática pedagógica.

\section{INTRODUCCIÓN}

El estudio se realizó, por el interés de plantear una reflexión pedagógica a partir de los resultados de las pruebas EGRA (por sus siglas en inglés Early Grade Reading Assement) y las estrategias de fluidez y comprensión lectora, implementadas en los centros educativos que atiende Fe y Alegría Nicaragua, como Movimiento de Educación Popular Integral y de Promoción Social

El equipo investigador encontró que, en el 2016, únicamente el $23 \%$ del estudiantado de los centros atendidos por la institución leía con fluidez y el 36\% comprendía lo que leía, esto dio como resultado el planteamiento del problema de investigación, el cual está en concordancia con lo que expresa la experta en temas educativos, Vanesa Castro, quien señala las deficiencias existentes en fluidez y comprensión lectora, como resultado de la aplicación de las pruebas EGRA en Nicaragua (Castro, 2012).

Otro gran problema señalado por la autora es el hecho de que, en Nicaragua, el profesorado no se nutre de las investigaciones educativas; por tanto, esto significa un bajo desempeño en su labor docente.

A partir de estos problemas, y las preguntas de investigación planteadas, se propusieron tres grandes objetivos: el primero fue valorar los niveles de avance en fluidez y comprensión lectora del estudiantado de primero a tercer grado, en los cursos escolares 2016, 2017 y 2018; el segundo, identificar los factores que influyen en el proceso de fluidez y comprensión lectora en el estudiantado, y el tercero, evaluar la propuesta de mejora de fluidez y comprensión lectora aplicada hasta el momento y actualizarla con aportes de docentes de primero, segundo y tercer grado de los centros educativos participantes.

Las pruebas estandarizadas EGRA, permiten "valorar con rapidez el dominio de competencias indispensables para el aprendizaje de la lecto-escritura que tienen los estudiantes de primero a cuarto grado" (Fundación Zamora Terán, 2013, p. 6). En cuanto al desempeño docente, tal como lo indica Díaz (2019) trazar una estrategia de transitoriedad, permite lograr resultados positivos ante los cambios de la sociedad actual, con docentes competentes en el uso de metodologías didácticas y recursos variados dentro del aula.

Por otro lado, tal como lo señala Castro (2012): 
De acuerdo con los hallazgos de la neurociencia, un niño al finalizar el primer grado, debe leer de 30-35 palabras por minuto y comprender lo que lee; si esta fluidez no se consigue, [la oportunidad] de mejorar en el segundo grado disminuye, porque el cerebro tiene ventanas que se abren y a medida que pasa el tiempo, no se abren con la misma facilidad. (párr. 43)

Según Fuchs, et al., (2001), se ha verificado que las pruebas orales de fluidez lectora cronometradas, miden las palabras leídas correctamente en un minuto, tienen una fuerte correlación (0.91) con la sub prueba de comprensión lectora de la Stanford Achievement test(como se cita en Jiménez, 2009, p. 45).

La finalidad de las pruebas orales es constatar si el estudiantado resulta capaz de escuchar un pasaje oral y luego responder a varias preguntas correctamente con una palabra o un enunciado simple (Jiménez, 2009, p. 48). Por otro lado, Condemarin (2006) señala que, cuando el estudiantado lee correctamente, de forma fluida y consistente, se auto motiva y genera procesos internos que ayudan a enfrentar lo académico de forma exitosa (como se cita en Molina, 2014, p. 17).

El presente estudio, representa un esfuerzo realizado por Fe y Alegría Nicaragua, al documentar el desempeño estudiantil en los primeros grados de educación primaria, para medir los avances obtenidos a partir de la aplicación de la propuesta de mejora de la calidad educativa en el estudiantado. De igual manera, se considera a la persona docente, un factor clave en el aprendizaje del estudiantado; por tanto, sus aportes en este estudio son de suma relevancia.

Este trabajo de investigación se convirtió en una radiografía para la Fe y Alegría Nicaragua; pues determinó los avances en fluidez y comprensión lectora del estudiantado, pero también los desafíos; permitió comprobar que hasta el 2018, Fe y Alegría utilizaba estándares de medición propios de la institución, los cuales estaban por debajo del estándar internacional. Por lo anterior, se realizó una comparación de los logros de aprendizaje del estudiantado y se usó tanto el estándar de Fe y Alegría como el internacional, se encontró que una parte importante de estudiantes, alcanzaba o superaba los estándares internacionales. En este sentido, se comprobó que el rol de docentes y familiares de estudiantes es muy importante en el proceso de lectoescritura.

Este estudio, se constituyó en una herramienta diagnóstica muy importante; pues permitió visualizar con claridad los estándares de medición de las pruebas estandarizadas, además de proporcionar herramientas didáctico pedagógicas para la mejora de la calidad educativa, a partir de las experiencias exitosas de personas docentes que imparten clases en los primeros grados.

\section{MATERIALES Y MÉTODOS}

La investigación tiene un enfoque mixto, puesto que se plantean paradigmas de investigación cuantitativa y cualitativa; además se aplica el método hermenéutico entendido como: "una actividad interpretativa que permite la captación plena del sentido de los textos en los diferentes contextos por los que ha atravesado la humanidad". (Arráez, Calles, y Moreno, 2006 p. 174)

El nivel de integración intermétodo del estudio resulta mínimo; es decir, se aplicó el Diseño Integral Complementado (DICO), el cual según Villalobos (2017, p. 414) la integración ocurre en la interpretación de los datos obtenidos de los metodos involucrados, al tiempo que conservan su naturaleza cualitativa o cuantitativa.

El estudio es de corte longitudinal, dado que se estudia un fenómeno en tres años consecutivos. La muestra de 4.624 se obtuvo a partir de una población de 5.820 pruebas a estudiantes de primero a tercer grado en 18 centros educativos distribuidos en los tres años correspondientes al estudio. Este muestreo 
acepta un $99.7 \%$ de confianza y un $1 \%$ de margen de error, se consideró de esta manera, para que el estudio tuviera un mayor nivel de confiabilidad en sus resultados.

Los 18 centros participantes están distribuidos en todo el territorio nacional, tres en la región norte, (Estelí, Ocotal), seis en la región de Ciudad Sandino, Managua y Matearea, nueve en Occidente (León, Chinandega, Somotillo), de los cuales seis centros multigrados; es decir, donde la persona docente atiende en el mismo momento tres grados, los cuales suelen ser $1^{\circ}, 2^{\circ}$ y $3^{\circ}$, o bien $4^{\circ}, 5^{\circ}$ y $6^{\circ}$.

Hasta el 2016, las pruebas EGRA únicamente se aplicaban a los primeros grados de educación primaria en Fe y Alegría; sin embargo, dado los resultados obtenidos en ese año, se optó por dar un seguimiento del avance que el estudiantado tenía en segundo y tercer grado. En la tabla 1, se presenta la distribución de la población y muestra de las pruebas analizada en los tres años.

TABLA 1

Cantidad de pruebas aplicadas en estudiantes de primer a tercer grado del 2016 al 2018

\begin{tabular}{|c|c|c|c|c|c|c|c|c|}
\hline \multirow{2}{*}{ GRADO } & \multicolumn{2}{|c|}{2016} & \multicolumn{2}{|c|}{2017} & \multicolumn{2}{c|}{2018} & \multicolumn{2}{|c|}{ N TOTAL } \\
\hline & $\mathrm{N}$ & $\mathrm{n}$ & $\mathrm{N}$ & $\mathrm{n}$ & $\mathrm{N}$ & $\mathrm{n}$ & $\mathrm{N}$ & $\mathrm{n}$ \\
\hline $\mathbf{1}^{\circ}$ & 956 & 760 & 940 & 747 & 1014 & 805 & & \\
\hline $\mathbf{2}^{\circ}$ & 0 & 0 & 972 & 772 & 944 & 750 & & \\
$3^{\circ}$ & 0 & 0 & 0 & 0 & 994 & 790 & & \\
& $\mathbf{9 5 6}$ & $\mathbf{7 6 0}$ & $\mathbf{1 9 1 2}$ & $\mathbf{1 9 1 2}$ & $\mathbf{2 9 5 1}$ & $\mathbf{2 3 4 5}$ & $\mathbf{5 8 2 0}$ & $\mathbf{4 6 2 4}$ \\
\hline
\end{tabular}

Nota: Esta tabla presenta la población y muestra de pruebas que se utilizaron en el estudio, según años y grado de escolaridad Fuente: Elaboración propia.

Para la investigación cualitativa, se efectuó un total de 20 entrevistas a docentes de primero a tercer grado de seis centros educativos unigrados, los cuales se definen como aquellos grados donde la persona docente solo atiende un solo grado y dos centros educativos multigrados, en los cuales la persona docente atiende tres grados $\left(1^{\circ}, 2^{\circ}\right.$ y $\left.3^{\circ}\right)$, además se realizaron cinco grupos focales en centros educativos ubicados en diferentes partes del país. En este estudio se utilizará el término región a lo largo de la presentación de los resultados, esto se debe a que en la institución al momento de realizar el estudio, contaba con tres equipos territoriales, un equipo ubicado en la región norte, que atendía los tres centros educativos que Fe y Alegría acompaña en los municipios de Estelí y Ocotal; otro equipo, que atiende los centros educativos ubicados en León, Chinandega y Somotillo, y un tercer equipo que atiende los centros educativos ubicados en Managua, Ciudad Sandino y Mateare.

\section{Análisis de la información}

En cuanto al procesamiento de los datos, se utilizaron dos tipos de parámetros de velocidad lectora, uno establecido institucionalmente por Fe y Alegría, y el estándar internacional, el cual según la literatura revisada, establecía que un estudiante al finalizar el primer grado debería leer 45 palabras por minuto, al final del segundo grado 60 palabras por minuto y al final del tercero 90 palabras por minuto. (Jarquin, 2014, párr. 7) 
Para una mayor objetividad de los resultados, se aplicó la fórmula de velocidad lectora VL= PLPM/t*60.

Donde VL= Velocidad Lectora.

PLPM= Palabras leídas por minuto

$\mathrm{t}=$ tiempo

Esta fórmula está de conformidad con el inciso 7 de la sección VI del Manual para la Evaluación Inicial de la lectura en niños de educación primaria. (Jiménez, 2009, p. 59)

Una vez creada la base de datos que se utilizó en el estudio con la información de los tres años, estos se procesaron mediante los programas de análisis de datos cuantitativos (SPSS, por sus siglas en inglés Statistical Package for the Social Sciences) y datos cualitativos (Atlas Ti).

Con el SPSS se llevaron a cabo las pruebas de consistencia interna, se cruzaron variables de interés; en tanto, las tablas y los gráficos se elaboraron y diseñaron por medio de Excel. En cuanto al Atlas ti, permitió la realización de codificaciones, creación de vistas de red.

El análisis de las pruebas EGRA constó de dos momentos; por un lado, se logró establecer parámetros de comparación entre las pruebas aplicadas a estudiantes de primer grado en los tres años y, por otro lado, se logró ver el avance que el estudiantado había tenido durante la aplicación de las pruebas EGRA, desde primer grado hasta tercer grado, así se dio respuesta al primer objetivo específico de esta investigación.

En cuanto a los factores que influyen en el proceso de fluidez y comprensión lectora y la evaluación de la propuesta de mejora de la fluidez y comprensión lectora, se logró realizar cruces de categorías mediante la triangulación de datos, se obtuvo información relevante por parte de docentes y estudiantes que participaron en el estudio.

El equipo de investigación, presentó el protocolo a los coordinadores regionales de Fe y Alegría Nicaragua, para darles a conocer el objetivo del estudio e invitarlos a formar parte activa del proceso y, al mismo tiempo, se les solicitó la autorización por escrito para el desarrollo de la investigación a las o los directores de los centros educativos; asimismo, se redactó un consentimiento informado para docentes y estudiantes que participaron de las entrevistas y los grupos focales, en el cual se explicaba el propósito de la investigación y todas las consideraciones éticas correspondientes al estudio.

\section{DISCUSIÓN DE RESULTADOS}

A partir de la aplicación de las pruebas EGRA en los primeros grados de educación primaria del 2016 al 2018, permitió realizar una reflexión pedagógica de cómo estaban las comunidades educativas en cuanto al proceso de lecto-escritura en los primeros grados, los resultados de este estudio se constituyó en una línea base, la cual permitió dar seguimiento a este proceso en los años subsiguientes.

El primer hallazgo que se encontró en este estudio, fue que los estándares de medición utilizados por Fe y Alegría, diferían de los estándares internacionales; por tanto, se hizo necesario establecer unos parámetros de comparación, los cuales permitieran visualizar el porcentaje de estudiantes que alcanzaban el estándar de Fe y Alegría, y quiénes alcanzaban el estándar internacional.

En la tabla 2 se presentan tanto los estándares definidos institucionalmente, como los internacionales. En primer lugar, de acuerdo con el estándar internacional, un estudiantado al finalizar el primer grado debería leer 45 palabras en un minuto, y al finalizar segundo 60 palabras en un minuto; sin embargo, Fe y Alegría definía diez palabras menos en estos dos niveles educativos. 
En tercer grado, el estándar establece que el estudiantado debería leer 90 palabras en un minuto, en el caso de Fe y Alegría definía 20 palabras menos.

Al conocer esta información, para Fe y Alegría se convirtió en un desafío definir como parámetro de medición el estándar internacional a la hora de aplicar las pruebas en los años subsiguientes.

TABLA 2

Estándares de fluidez lectora

\begin{tabular}{|cccc|} 
Niveles & Valoración & Indicador Fe y Alegría & Indicador internacional \\
\hline $\mathbf{1}^{\circ}$ grado & Lee con fluidez & Más de $35 \mathrm{plpm}$ & Más de $45 \mathrm{plpm}$ \\
\hline $\mathbf{2}^{\circ}$ grado & Lee con fluidez & Más de $35 \mathrm{plpm}$ & Más de $60 \mathrm{plpm}$ \\
\hline $\mathbf{3}^{\circ}$ grado & Lee con fluidez & Más de $35 \mathrm{plpm}$ & Más de $90 \mathrm{plpm}$ \\
\hline
\end{tabular}

Nota: Esta tabla presenta los indicadores obtenidos de informes de los resultados de las pruebas EGRA 2016, 2017, 2018 Fe y Alegría e indicadores retomados por el Instituto de Aprendizaje Ágil, CIACES (Jarquín, 2014).

Fuente: Elaboración propia.

\section{Niveles de avance en fluidez y comprensión lectora en los primeros grados de educación primaria (2016 -2018)}

Uno de los fines de esta investigación fue valorar los niveles de avance en fluidez y comprensión lectora del estudiantado de primero a tercer grado del 2016 al 2018. En la figura 1, se presentan los porcentajes de estudiantes que alcanzaron el estándar internacional, de tal forma que permite visualizar el avance comparativo entre los primeros grados y el avance evolutivo de primero a tercer grado.

Los resultados de estas pruebas, evidencian que del 2016 al 2018 hubo un avance paulatino del 23\% al $38 \%$ de estudiantes que alcanzaron el estándar internacional. En relación con el porcentaje del avance evolutivo, se observa que, en segundo grado, el porcentaje de estudiantes que alcanzaron el estándar internacional, está por encima del 75\% y en tercer grado se ubica por encima del 95\%, lo cual evidencia que las estrategias de fluidez y comprensión contempladas en la propuesta de mejora obtuvieron resultados satisfactorios.

\section{FIGURA 1}

Avance evolutivo y comparativo en fluidez lectora (2016-2018), según el estándar internacional

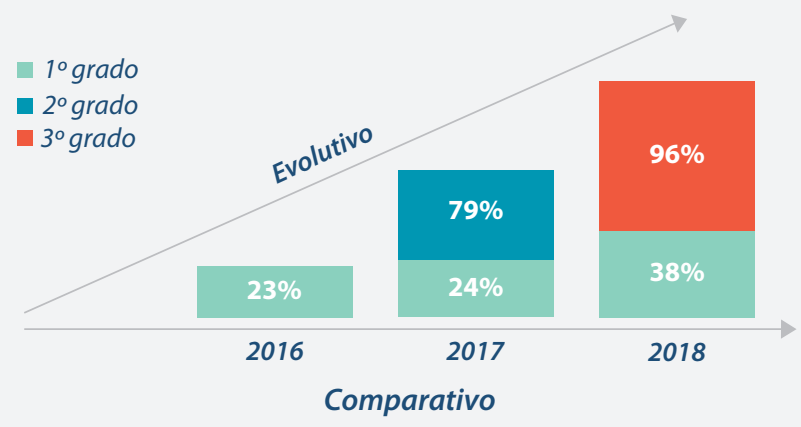

Nota: La figura presenta el porcentaje de estudiantes que alcanzaron el estándar internacional en los primeros grados de los años 2016, 2017 y 2018, y el avance evolutivo del estándar internacional alcanzado por el estudiantado de primer a tercer grado del 2016 al 2018.

Fuente: Elaboración propia. 
En cuanto a la comprensión lectora, en la figura 2 se presenta el promedio porcentual de respuestas correctas obtenidas por el estudiantado de primer grado en el periodo (2016-2018). En primer lugar, se observa que, en promedio el $47.3 \%$ de estudiantes que estaban en primer grado en los años 2016, 2017 y 2018, lograron comprender la primera pregunta presentada durante la aplicación de las pruebas.

Ahora bien, este porcentaje comienza a bajar en forma paulatina a medida que avanza la cantidad de preguntas realizadas; por tanto, al llegar a la pregunta 5, únicamente el $19.7 \%$ de estudiantes comprenden esta pregunta; dicho de otra manera lo anterior, a medida que aumenta el número de la pregunta, disminuye el porcentaje de comprensión lectora en el estudiantado; por tanto, se hace necesario aumentar los esfuerzos para que el estudiantado alcance mayores niveles de comprensión.

FIGURA 2

Promedio porcentual de comprensión lectora del estudiantado de primer grado del 2016 al 2018

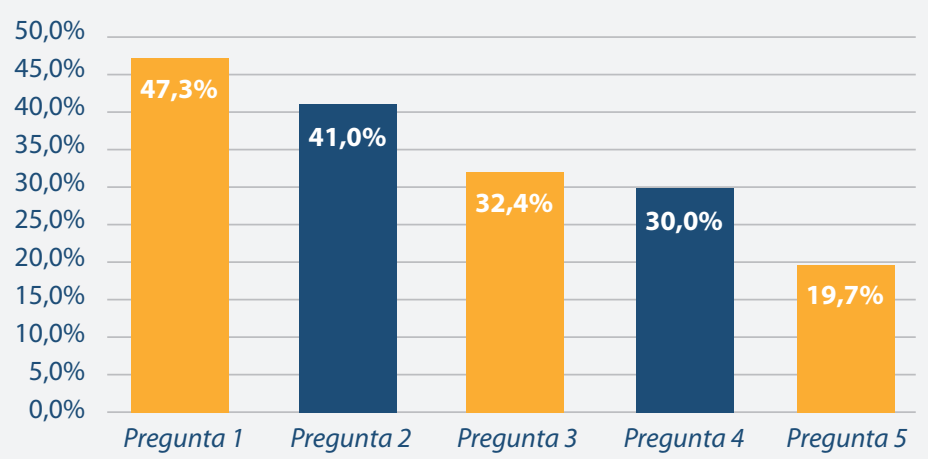

Nota: Este gráfico muestra el promedio porcentual de respuestas correctas obtenidas por el estudiantado de primer grado del 2016 al 2018.

Fuente: Elaboración propia.

En cuanto al avance que hubo en los resultados de las pruebas EGRA, en estudiantes de primero a tercer grado, se realizó una comparación entre los estándares de Fe y Alegría y los estándares internacionales. En la tabla 3, se observa que en primer grado del 2016, más estudiantes (34\%) lograron el estándar de Fe y Alegría, en comparación con el estándar internacional (23\%), lo mismo ocurrió en segundo grado del 2017 , cuando el $85 \%$ de estudiantes alcanzaron el estándar de Fe y Alegría y solo el $79 \%$ alcanzó el estándar internacional. En cambio, en tercer grado, se observa que el 96\% de estudiantes alcanzó tanto el estándar de Fe y Alegría como el internacional.

Este hallazgo, permitió que se optara por utilizar el estándar internacional como parámetro de medición a nivel institucional, para evaluar el desempeño en fluidez lectora del estudiante. Por otro lado, es importante señalar lo que indica Vanesa Castro, experta en temas educativos de Nicaragua, "para que la población pueda exigir calidad, es necesario decirles cuántas palabras por minuto debe leer un niño o niña al finalizar el primer, segundo o tercer grado" (Entrevista, 27 de junio, 2019). 
TABLA 3

Comparación de estándares de fluidez lectora de $1^{\circ}$ a $3^{\circ}$ grado (2016-2018)

\begin{tabular}{ccc|}
\hline Años & Estándar FYA & Estándar Internacional \\
\hline $1^{\circ}$ Grado (2016) & $34 \%$ & $23 \%$ \\
\hline $2^{\circ}$ Grado (2017) & $85 \%$ & $79 \%$ \\
\hline $3^{\circ}$ Grado (2018) & $96 \%$ & $96 \%$ \\
\hline
\end{tabular}

Nota: La tabla muestra la distribución porcentual de estudiantes que alcanzaron los estándares definidos tanto para Fe y Alegría como internacionalmente.

Fuente: Elaboración propia.

Respecto a la comprensión lectora de estudiantes de primero a tercer grado, en la figura 3 se presentan los porcentajes de estudiantes de primero a tercer grado que lograron comprender de la pregunta 1 a la 5 en los años 2016, 2017 y 2018. En primer grado, se observa el menor porcentaje de comprensión, las preguntas 4 y 5 son las que obtuvieron el menor porcentaje (19\% y 9\% respectivamente).

En segundo grado, se encontró que las preguntas 1 y 4 son las que obtuvieron el menor porcentaje de estudiantes que la contestaron correctamente, este dato es importante de rescatar, porque indicaba que, aunque el nivel de fluidez lectora en segundo grado era satisfactorio, el nivel de comprensión lectora era deficiente.

En tercer grado, solamente el $8 \%$ de estudiantes logró la comprensión de la pregunta 5, esto indicaba que existe una relación directa entre la fluidez lectora y la comprensión lectora; sin embargo, era necesario continuar fortaleciendo los niveles de comprensión en el estudiantado.

\section{FIGURA 3}

Comprensión lectora del estudiantado de primero a tercer grado del 2016 al 2018

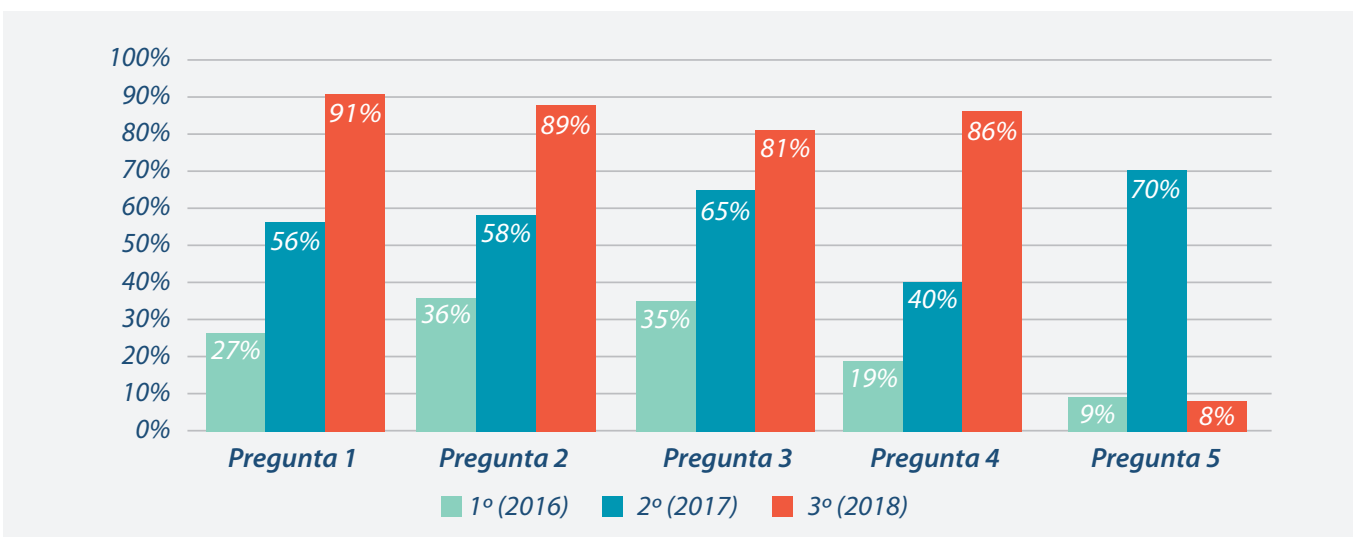

Nota: En el gráfico se presentan los porcentajes de estudiantes que alcanzaron a comprender correctamente de la pregunta 1 a 5 según avance evolutivo.

Fuente: Elaboración propia.

Para profundizar en el análisis evolutivo de los avances de comprensión lectora en los colegios atendidos por Fe y Alegría y los cuales participaron en el estudio, se presentan los resultados de comprensión de la pregunta 1 en contraste con los porcentajes del estudiantado que logró comprender la pregunta 5. 
En segundo grado, se observó que más estudiantes (70\%) lograron comprender la pregunta número 5 , en comparación con los que lograron la comprensión de la pregunta 1 (56\%), este hallazgo permitió inferir la mecanización de la lectura en segundo grado; pues, aunque el estudiantado logra leer con fluidez, tiene mayor dificultad para comprender las preguntas que se le plantean.

En primero y tercer grado se encontró que el porcentaje de estudiantes que logró la comprensión de la pregunta 5 es muy bajo ( $9 \%$ y $8 \%$ respectivamente); en tanto, en primer grado el $27 \%$ alcanzó la comprensión de la pregunta 1; sin embargo, en tercer grado, el porcentaje que logró la comprensión de la pregunta 1 es significativamente más alto (91\%).

Este hallazgo permitió relacionar las variables de fluidez lectora con las de comprensión lectora, porque se puede concluir que, a mayor cantidad de palabras leídas correctamente en un minuto, mayor es la probabilidad que el estudiantado tiene para comprender las preguntas que se le plantean.

FIGURA 4

Comprensión de las preguntas 1 y 5 , de $1^{\circ}$ a $3^{\circ}$ grado de 2018

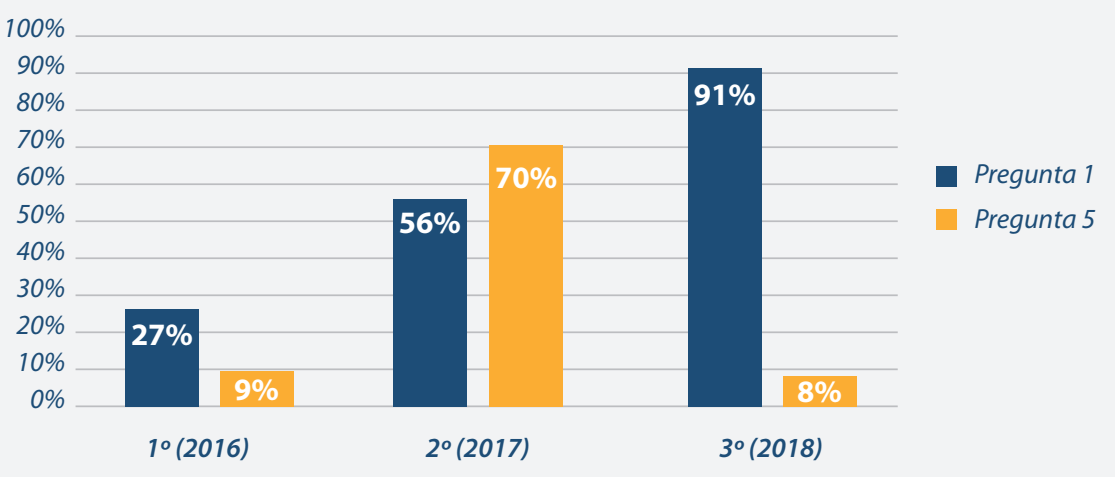

Nota: El gráfico presenta los porcentajes de comprensión lectora de las preguntas 1 y 5 del estudiantado de primero a tercer grado.

Fuente: Elaboración propia.

\section{Factores que influyen en el proceso de fluidez y comprensión lectora en el estudiantado}

Existen diferentes factores que condicionan la adquisición de la lectoescritura (Narvarte, 2008, p. 16). Por ello es que para fines de esta investigación, se propuso identificar cuáles factores influyen en el proceso de fluidez y comprensión lectora del estudiantado.

En las entrevistas realizadas a las docentes de primero a tercer grado de centros educativos ubicados en las tres regiones donde Fe y Alegría tiene presencia, se pudo constatar que los factores que se presentan en este estudio están relacionados tanto con el estudiantado, el profesorado como familiares responsables.

En primer lugar, en los factores pedagógicos se destaca el rol del profesorado y su desempeño como agente de enseñanza (Narvarte, 2008, p. 17). Para fines de este estudio, los factores pedagógicos se clasifican en factores pedagógicos internos y factores externos. Los internos están vinculados directamente con el profesorado como individuo: su preparación académica, capacidad autodidácta y su competencia lectora; los factores externos están relacionados con los procesos de formación docente, 
tiempo que dedica al planeamiento didáctico, conocimiento, acceso y uso de recursos tecnológicos y didácticos y la implementación de estrategias pedagógicas.

En relación con los factores pedagógicos internos del profesorado, se encontró que las y los docentes que imparten $1^{\circ}, 2^{\circ}$ y $3^{\circ}$ grado de educación primaria ostentan un título de Maestros de Educación Primaria, en ocasiones con títulos en diplomados facilitados por la Universidad Centroamericana (UCA), por medio de Fe y Alegría, o bien, licenciaturas en Pedagogía y Psicología y Máster en Didáctica y Educación.

La persona autodidacta "es la que aprende con sus propios medios y que se va estableciendo él mismo un plan de estudios con el fin de saciar su necesidad de formación e información sobre uno o varios temas en concreto" (Universia, 2020, párr. 3), si se toma el anterior concepto como referencia, desde la perspectiva del profesorado, todas y todas se consideran autodidactas.

Un ejemplo de persona autodidacta es lo mencionado por la docente de tercer grado del Colegio San Francisco Javier, quien señaló: "soy autodidacta porque tengo prioridad por mi educación y actualización personal e individual con mis propios medios y recursos; me he actualizado [a través] de internet, libros, y registro mis propias experiencias educativas" (Entrevista, RCSSFJ3 ${ }^{\circ}$ ).

Otras personas docentes entrevistadas se consideran autodidactas porque elaboran sus propios materiales para clases o bien, porque investigan estrategias y actividades y los temas que no aparecen en los libros los buscan por su propia cuenta.

En cuanto a la competencia lectora, varios autores la definen como "la capacidad que tiene el individuo de leer y comprender su entorno para desarrollar sus conocimientos y participar plenamente en la sociedad" (Castro, Cifuentes, Gómez, y Rincón, 2017 p. 1045).

Al respecto, se encontró que esta competencia en el profesorado varía de una escuela a otra en la misma región y en la misma modalidad, un ejemplo de ello es el caso de las docentes de las escuelas multigrados; mientras una persona docente dijo que es una buena lectora y que comprendía lo que leía, la otra afirmó tener dificultad en la comprensión de algunos contenidos.

En definitiva, se puede concluir que, los factores pedagógicos internos, son necesarios en la mejora de la fluidez y la comprensión lectora. En ese sentido, la formación académica es importante; pues dota al profesorado de herramientas didáctico pedagógicas, necesarias para el desarrollo del proceso lector; por otro lado, tanto el autodidactismo como el hábito lector, son indispensables para la autoformación permanente del profesorado.

Ahora bien, para fines de esta investigación, los factores pedagógicos externos están relacionados con el desempeño docente. Entre las formaciones que el profesorado ha recibido destacan las siguientes: pautas didácticas, comprensión lectora, actualización del Método FAS (Fónico, Analítico, Sintético), formación de líderes, prevención de daños ante desastres naturales, uso y manejo de las Tecnologías de la Información y la Comunicación (TIC), formación en educación Montessori y educación inclusiva, disciplina consciente, estrategias innovadoras, gestión pedagógica, cursos de metodología, actualización de biblioteca, intercambios de experiencias, profesionalización de multigrados, enfoque de resolución de problemas y lenguaje de señas. Estas formaciones son impartidas tanto por Fe y Alegría como por el Ministerio de Educación.

Las formaciones son de suma importancia en el desempeño docente; pues ayudan al profesorado a despertar interés en la niñez, con el fin de mejorar sus niveles de comprensión lectora, fortalecer la calidad de su trabajo y su práctica educativa.

Una persona docente que imparte primer grado en una escuela de modalidad regular señala: "yo aplico en mi aula todos los conocimientos, realizo lecturas a través del componedor individual y colectivo, 
además les dejo que practiquen lecturas diarias en sus casas" (Entrevista, RCSPB $1^{\circ}$ ). Por otro lado, una persona docente de la modalidad multigrado señaló: "me ha permitido ampliar mis conocimientos, implementar y recrear estrategias que motivan al estudiante hacia la lectura" (Entrevista, ROSFM).

Lo anterior denota, como los procesos de formación en los cuales participa el profesorado; por un lado le permite mejorar su desempeño docente $y$, por otro, incidir de forma positiva en el proceso de aprendizaje del estudiantado.

En relación con el planeamiento didáctico, García y Valencia (2014) consideran que "hablar de la planeación didáctica, es referirse al estudio de los criterios básicos de la planeación, en particular la necesidad de considerar la relación entre los propósitos educativos, las características de los alumnos y la articulación del contenido" (p. 18). Al respecto, el tiempo que las y los docentes dedican al planeamiento varía de un centro educativo a otro y de una región a otra, el cual oscila entre dos y siete horas.

Los recursos tecnológicos usados con mayor frecuencia en los procesos de aula están: computadora, data show, reproductores, celular, tabletas, televisor, grabadoras. Estos recursos los utilizan para aplicar estrategias como: la lectura en karaoke, presentación de imágenes, presentación de videos, escuchar cuentos y uso de programas interactivos.

Los recursos didácticos utilizados con mayor frecuencia son: el uso de láminas, carteleras con imágenes, fichas didácticas, cuentos, trabalenguas, pizarra, rotafolio, material del medio, tarjetas, dinámicas, sopas de letras, crucigramas, rompecabezas, lecturas variadas, acción didáctica, plan diario, componedor, las PEM, "chalupa", uso del diccionario. Estos recursos didácticos se usan para realizar trabajos en grupo o individuales.

Las estrategias pedagógicas son "todas las acciones realizadas por el docente con el fin de facilitar la formación y el aprendizaje [del estudiantado]" (Gamboa, García, y Beltrán, 2013, p. 103); por tanto, deben ser acciones enriquecidas por su formación académica y profesional, y con un profundo conocimiento del grado que imparte.

Dentro de los factores sociales, según Narvarte (2008) "se consideran las características del medio ambiente al que el niño pertenece y las características familiares" (p.20). En un estudio realizado por Rodríguez y Capataz (2015) encontraron que "el bajo nivel educativo de los padres [y madres] de familia (algunos analfabetos y otros con un nivel inferior a la secundaria) dificultaba el acompañamiento curricular [de sus hijos e hijas]" (p. 21).

En este estudio, se halló que el contexto familiar del estudiantado varía de un centro educativo a otro, en algunos centros educativos, los responsables familiares del estudiante cuentan con recursos económicos y una preparación académica que les permite reforzar los aprendizajes del estudiantado; en cambio, en otros centros educativos, los responsables familiares no cuentan con recursos económicos y tampoco con preparación académica; pues algunas madres y padres son analfabetas, no saben leer y escribir, y esto les dificulta poder ayudarles a sus hijas e hijos a avanzar en su proceso de aprendizaje.

\section{Percepción que el estudiantado tiene sobre el proceso de lectoescritura}

El estudiantado percibe el proceso de lectoescritura de manera diferente, en dependencia del contexto educativo, esto se refleja por ejemplo, en el hecho de que las niñas y los niños de la región norte, y las niñas y los niños de las escuelas multigrados consideran que leen bien y son capaces de contestar preguntas relacionadas con el texto; en cambio, las niñas y los niños de los centros educativos de la región de Ciudad Sandino, Managua, Mateare dijeron que la mayoría lee cancaneado; es decir, realizan una lectura sin fluidez, aunque si se consideran capaces de contestar preguntas después de haber leído. 
En el estudio se constató que los centros educativos, donde el profesorado lee diariamente a sus estudiantes, los resultados a partir de la aplicación de las pruebas EGRA son más positivos en aquellos centros educativos, donde no se realiza la lectura diaria y se utiliza el dictado como parte de los métodos de enseñanza.

De igual manera, el estudiantado percibe de forma diferente la manera cómo lee la maestra o el maestro. En algunos centros educativos, refirieron que la docente leía bonito, despacio, que no se equivocaba, que tenía fuerza para leer y respeta los signos de puntuación y ortografía; en cambio, en otros centros educativos el estudiantado se limitó a señalar que la persona docente leía bien, ya fuera porque leía rápido, o porque leía con calma y despacito.

En relación con la forma en cómo leen las personas docentes, se ha comprobado que para que un estudiante comprenda lo que lee, es necesario que maestras y maestros les lean bien (con sentido y gracia); necesitan que les soliciten la opinión de lo que han escuchado, reflexionen sobre lo que han leído y relacionen lo leído con su vida (Castillo, 2015). Según la autora, "si no hay tiempo para desarrollar las destrezas de la comprensión, que son las que forman seres humanos pensantes, no hay calidad en la educación" (Castillo, 2015, párr. 21).

En cuanto al proceso lector, Ariza y Vargas (2017) señalan que, el profesorado "debe realizar una reevaluación y tomar acciones encaminadas a mejorar las competencias lectoras en el aula, es por ello que en todas las asignaturas se deben dirigir esfuerzos para fortalecer las competencias para desarrollar con éxito el proceso lector". (p.75)

Desde la percepción del estudiantado, se encontró que en algunos centros educativos las y los docentes hacen hincapié en las normas de convivencia, antes de iniciar el proceso de lectura; en otras, se observa una contradicción en la orientación que la docente da antes de comenzar la lectura; por un lado, les solicita que se sienten y guarden silencio, y por otro, que saquen lápiz y cuaderno. Por ello, durante la lectura, las niñas y los niños refieren que hacen alboroto o indisciplina, unos hablan y otros copian, lo anterior, evidencia que el profesorado debe ser consciente de la importancia de la disciplina escolar: por tanto, debería aplicar estrategias, como por ejemplo: los cinco minutos de silencio, utilizados antes de aplicar las PEM (Pequeñas Entradas Matemáticas).

En los centros donde se aplicaba correctamente el proceso lector, el estudiantado señaló que antes de iniciar la lectura, leían el título de la lectura, inventaban un título a la lectura; luego procedían a realizar la lectura modelo (realizada por la docente); durante este tiempo en las escuelas donde se inicia la lectura de esta manera, casi siempre el estudiantado se mantiene en silencio; en el último componente del proceso el estudiantado hace mención de la lectura silenciosa, la lectura coral, trabajo colaborativo, uso del diccionario y la transcripción de cuentos; sin embargo, hubo centros educativos en los cuales el estudiantado no hizo referencia a este momento del proceso lector.

Sobre los niveles de comprensión lectora, la mayoría de las preguntas que las y los estudiantes mencionaron corresponden al nivel literal; no obstante, también se mencionaron unas pocas preguntas del nivel inferencial y crítico.

El tercer elemento importante en este apartado es el referido a los recursos u oportunidades que el estudiantado tiene para leer. En primera instancia, se observó que algunos estudiantes mencionan elementos como libros, copias, papelógrafos, pizarra, tarjetas, entre otras. Asimismo, se observó que algunos mencionaron que leían en la sala de computación; en contraste, en algunas escuelas las y los estudiantes mencionaron que no hay libros de texto para todo el salón de clases.

Las lecturas más sobresalientes son los cuentos, historias, leyendas, pero también se mencionaron lecturas relacionadas con la naturaleza, los valores, los sentidos, los meridianos; además se observó la lectura de trabalenguas. 
En relación con el gusto por la lectura, algunos estudiantes señalaron que les gustaba leer, en cambio, otros dijeron que no porque les daba pena leer en voz alta por temor a que sus compañeros se burlaran de ellos, o bien porque no tenían fluidez.

En cuanto al uso de la biblioteca, todos los centros, a excepción del centro multigrado participante, tienen biblioteca; sin embargo, en algunas escuelas hacen uso de este espacio, en otros centros educativos no. Por otro lado, algunos estudiantes refirieren que les gustar ir porque van a leer y jugar con los legos; otros en cambio, indican que no les gusta ir a la biblioteca porque es aburrida.

El cuarto elemento es el rol de la familia en el proceso de lectoescritura; en este último, se observó que, en algunos centros educativos, la mayoría de los niños y niñas tienen libros en sus casas, en cambio, en otros centros educativos no, lo cual evidencia una realidad distinta para cada grupo de estudiantes.

Entre los familiares que les leen libros a los niños y las niñas en todos los centros educativos sobresale la figura de la mamá, el papá, la abuela, el abuelo, tíos, hermanos y en relación con las personas que les facilitan los libros (comprados o regalados) destacan la figura de la mamá, abuelas, tías, madrinas y vecinas.

En conclusión, las niñas y los niños perciben el proceso de lectoescritura de diferente manera; además las oportunidades que tienen de acceder a la lectura es desigual, por otro lado, el profesorado y la familia juegan un papel importante en el proceso de fluidez y comprensión lectora

\section{Propuesta de mejora de la fluidez y la comprensión lectora}

Por otro lado, desde el punto de vista de varios autores, la escuela es "un espacio de integración, interacción y sinergia" (Marín, et al., s.f., p. 4), en el cual el estudiantado puede sacar el máximo provecho de sus potencialidades. Dentro de las escuelas, la biblioteca escolar es un espacio de singular relevancia, que permite fomentar el amor a la lectura [comprensiva]; este espacio, según Delgado (2007) debe ser "un lugar acogedor y atractivo, con diversidad de material didáctico y tecnológico donde se pueda facilitar la búsqueda y exploración a través de la lectura" (como se cita en, Ariza \& Vargas, 2017, p. 74). Para las y los docentes entrevistados, los ambientes de lectura varían de un centro educativo a otro y, en algunas escuelas, estos espacios no existen.

En cuanto a las estrategias que las y los docentes recomiendan para mejorar la fluidez están el tesoro escondido, la lectura eco, la lectura silenciosa, entre otras y la lectura coral con un nivel avanzado.

El tesoro escondido, consiste en que los niños encuentren el tesoro, leen la pregunta y la contestan, en tanto la lectura eco consiste en que la maestra lee y el estudiantado lee con la misma entonación con la que lo hizo la maestra.

Otras estrategias señaladas son el uso del silabario, cuentos en hojas, dictados de oraciones y su posterior lectura en voz alta, la descripción de láminas, lectura silenciosa, ilustración de la lectura, formación de palabras y oraciones en el componedor, la caminata lectora, lectura pictográfica, lectura de carteles, lectura cronometrada y el recorrido de la lectura.

En cuanto a las estrategias para mejorar la comprensión lectora recomendaron las siguientes.

- Uso de láminas e imágenes creativas para las predicciones del contenido del texto.

- Escuchar un texto e ilustrar posteriormente el contenido de este.

- Sol Solecito: consiste en elaborar un sol llamativo [con material del medio], en la parte de atrás colocar tarjetas con preguntas relacionadas con la lectura que se leerá. 
- Uso de las lecturas adecuadas para el grado, realizar ejercicios de selección múltiple y verdadero y falso justificando la respuesta, además de realizar preguntas según los niveles de comprensión lectora: literal, inferencial, crítico.

- El dado preguntón que se puede trabajar con preguntas directas, y la cajita de regalos que consiste en colocar dentro de la cajita preguntas en donde el niño pasa, saca su pregunta y la contesta, y participa todo el grado.

- Análisis de cuentos mediante ilustraciones.

- Iniciar la clase con la lectura de un cuento para posteriormente entrar al estudio del fonema del día, también propusieron las lecturas similares a las utilizadas en las pruebas EGRA.

- El uso del diccionario para mejorar la ortografía, la caligrafía y enriquecer el vocabulario.

- Recreación de lecturas y realización de actividades lúdicas.

- Resolución de sopas de letras.

- Elaboración de cuentos pictográficos.

- Completar el cuento con el aporte de los discentes.

En definitiva, se observa que las y los docentes conocen y aplican técnicas y estrategias de fluidez y comprensión lectora en sus procesos de aula; sin embargo, se evidencia la necesidad de mantener un proceso de formación continua y permanente para lograr los resultados esperados en fluidez y comprensión lectora en el estudiantado.

En el 2017, el Consejo Técnico de Fe y Alegría validó la Propuesta de Fluidez y Comprensión lectora, esto originó un proceso de intervención, el cual ha sido reflexionado a lo largo de los resultados presentados en este trabajo de investigación. En este estudio se proponen ideas para actualizar la propuesta desde los aportes brindados por las y los docentes que participaron en el estudio.

Los espacios de formación de la estrategia de fluidez y comprensión lectora (2017-2018) se basaron en la metodología de Educación Popular. En la profundización de la estrategia se propusieron las siguientes acciones:

- Conocer ¿cómo aprenden a leer los niños y las niñas?

- Brindar herramientas para elaborar preguntas desde cada uno de los niveles: literal, inferencial, crítico.

- Enfoques pedagógicos efectivos.

- Generación de procesos de reflexión, intercambios y aprendizajes sobre: aula letrada, recursos didácticos y uso de biblioteca.

- En cuanto a las prácticas mejoradas se esperaba lo siguiente.

- Seguimiento a acuerdo en talleres de formación:
a) Aula letrada.
b) Uso de rincón de cuentos.
c) Planeación didáctica.
d) Estrategias de comprensión lectora en primer grado. 
- Registro de prácticas innovadoras de mejora de fluidez y comprensión lectora integrando la perspectiva de género.

Una de las debilidades encontradas en la propuesta de mejora de la fluidez y la comprensión lectora fue el desconocimiento de algunas personas docentes acerca de la existencia de la propuesta. De las ocho estrategias presentadas a las personas docentes, hubo casos en los cuales desconocían hasta seis de las ocho; este hallazgo dio como resultado la necesidad de crear espacios de divulgación, de modo que todas y todos las personas involucradas conozcan la propuesta de mejora de fluidez y comprensión lectora institucional.

Otro dato importante dentro de este indicador es que únicamente la Escuela San Antonio (multigrado) mencionó el aula letrada como estrategia de comprensión lectora, lo cual sigue evidenciando el desconocimiento de esta por parte de las y los docentes en las otras regiones.

En cuanto a la biblioteca en el aula, en la región norte no se implementa por la falta de espacio en los salones de clases; por otro lado, mencionan la importancia de estar renovando los libros [con lecturas llamativas para el estudiantado, según el nivel de escolaridad que cursa]. Por su parte, las y los docentes de la región de Ciudad Sandino consideran necesario tener espacios [adecuados] donde se pueda fomentar la concentración; además creen que se deberían tener libros de cuentos cortos que les llame la atención a los niños y las niñas.

En cuanto a la promoción de la lectura en voz alta, se debe sensibilizar al estudiante sobre la importancia de mantenerse en silencio mientras sus compañeros y compañeras de clases leen. Por otro lado, las personas docentes consideran que esta estrategia da mejores resultados con pocos estudiantes; por tanto, la organización de círculos de lectura con el apoyo de familiares, es una idea que puede fomentar el hábito de la lectura en la familia y la comunidad.

Otro elemento indispensable es promover la comprensión lectora desde el principio, tal como lo menciona Narvarte (2008): "en el proceso de enseñanza-aprendizaje de la lectura, la destreza rítmica y la comprensión deben darse simultáneamente" (p.47). Según los aportes de las personas docentes para mejorar esta estrategia, se debe priorizar la calidad del material [que se presenta a los niños y niñas]; estos deben ser llamativos y además tener un inicio y un final de la historia que se les presenta a los niños y las niñas; pues el uso de láminas es importante para fomentar la comprensión en el estudiantado. Por otro lado, destacan la importancia de que él o la docente de primero, segundo y tercer grado motiven a la niña o al niño a leer para que supere la timidez e inseguridad.

En cuanto a la organización de niños y niñas en grupos de similar nivel de lectura y escritura, algunas docentes proponen el apadrinamiento de niños y niñas el cual significa que niños y niñas con mejores niveles de aprendizaje, al finalizar sus actividades, puedan acompañar a los niños/as con dificultad, haciéndoles conscientes que deben ayudar a su par, pero que no deben hacerle los ejercicios.

En relación con los niveles de comprensión lectora: literal, inferencial y crítico para el periodo de estudio 2019-2021 se propone incluir en las pruebas EGRA preguntas en los tres niveles de forma progresiva, de tal manera que se pueda evaluar qué nivel de comprensión lectora logra alcanzar el estudiantado 


\section{SÍNTESIS Y REFLEXIONES FINALES}

El estudio permitió comparar los resultados obtenidos a partir de la aplicación de las pruebas EGRA a estudiantes de primero, segundo y tercer grado del 2016 al 2018, en ese sentido, se encontraron avances en fluidez lectora, tanto a nivel de los primeros grados en los tres años del estudio, así como un avance evolutivo de primero a tercer grado en el mismo periodo.

En cuanto a los niveles de comprensión se notó que, aunque un buen porcentaje del estudiantado alcanza a leer de acuerdo con los estándares internacionales, aún existe una brecha entre fluidez y comprensión lectora.

La investigación es relevante en el campo de las ciencias de la educación; pues aporta insumos necesarios relacionados con la valoración de las competencias de fluidez y comprensión lectora en estudiantes de primero a tercer grado. Por otro lado, a partir de los hallazgos, se pueden determinar indicadores de medición que permitan monitorear el avance del estudiantado en fluidez y comprensión lectora en los años subsiguientes; de tal manera que el profesorado cuente con información oportuna para dar seguimiento a sus procesos de aprendizaje.

Las personas docentes señalan la formación docente y los intercambios de experiencias como estrategias que han dado buenos resultados, tanto en su desempeño escolar como en el aprendizaje de sus educandos. El estudio da pautas para la evaluación del desempeño docente; pues aunque la aplicación de estrategias metodológicas son de suma relevancia, también es necesario contar con docentes investigadores, capaces de mantenerse en una autoformación permanente, para ofrecer respuesta a los desafíos de la mejora de la fluidez y la comprensión lectora del estudiantado.

Tal como lo refiere Narvarte (2008) "el maestro tiene un rol protagónico en el aprendizaje de la lectoescritura" (p. 22); por ello, en este estudio se consideró al docente como un informante clave durante el desarrollo de la investigación. Asimismo, el docente brindó aportes sustantivos para la actualización de la propuesta de mejora de la fluidez y la comprensión lectora para que se continúe aplicando en los centros atendidos por la institución.

\section{REFERENCIAS}

Ariza, C., \& Vargas, L. (2017). La indagación, pretexto para fortalecer la comprensión lectora. Revista Ciencias Humanas, 67-77.

Arráez, M., Calles, j., \& Moreno, L. (2006). La hermenéutica: una actividad interpretativa. Red de Revistas Científicas de América Latina, el Caribe, España y Portugal, 7(2):171-181.

Castro, V. (Marzo, 2012). Si no mejora la calidad en la educación pública está en juego el futuro del pais. Envío.

Castro, C., Cifuentes, N., Gómez, T., \& Rincón, N. (2017). Implicación de la formación de la competencia lectora: una visión desde el aula. En J. Gómez, A. Aguilar, S. Jaimes, C. Ramírez, J. Salazar, J. Contreras, \& J. Espinoza, Prácticas pedagógicas (págs. 1039-1065). Maracaibo: Astro Dasa S.A.

Castillo, M. (2015). Este estudio nos alerta: en la educación nos estamos quedando atrás. Recuperado de http://www.envio.org.ni/articulo/4963

Fundación Zamora Teran. (2013). Promoviendo el desarrollo de la lectoescritura en Nicaragua. Managua.

Gamboa, M. C., García, Y., \& Beltrán, M. (2013). Estrategias pedagógicas y didácticas para el desarrollo de las inteligencias múltiples y el aprendizaje autónomo. UNAD, 12(1): 101-128. 
Jarquin, L. (21 de Enero de 2014). Y usted,¿cuántas palabras lee por minuto? El Nuevo Diario. Tomado de: https://www.elnuevodiario.com.ni/especiales/308373-usted-cuantas-palabras-lee-minuto/.

Jímenez, J. (2009). Manual para la evaluación inicial de la lectura en niños de educación primaria. Islas canarias: RTI International.

Marin, F., Niebles, M., Sarmiento, M., \& Valbuena, S. (2017). Mediación de las tecnologías de la información en la comprensión lectora para la resolución de problemas aritméticos de enunciado verbal. Espacios.

Molina, D. (2014). El método Fonico Analítico-sintético orientado a la enseanza del código alfabético de los niños del segundo año de educación general básica de la escuela "Ambato de los Angeles" de la Parroquia Izamba del Cantón Ambato Provincia de Tungurahua. Ambata, Ecuador: Univerisdad Técnica de Ambata.

Narvarte, M. (2008). Lectoescritura: aprendizaje integral. España: Talleres gráficos Peñalara S.A.

Universia. 28 de diciembre de 2020. https://www.universia.net/cl/actualidad/orientacion-academica/ cual-es-el-significado-de-ser-autodidacta.html (último acceso: 30 de julio de 2021).

Villalobos, L. R. (2017). Enfoques y diseños de investigación social. San José: Universidad Estatal a Distancia. 